\title{
Quantification of bands produced by isoelectric focusing using immunoperoxidase
}

\author{
UH PALUCH, G KEIR, S MOYLE, EJ THOMPSON \\ From the Department of Clinical Neurochemistry, Institute of Neurology, Queen Square, London WC1N \\ $3 B G$.
}

SUMMARY An improved, rapid, and sensitive (to autoradiographic levels) method for the quantification of IgG bands from cerebrospinal fluid is presented. The principle of an internal standard is employed using the discrete bands of a paraprotein to correct for any run to run variability in the enzyme detection system which is linked to the immunoassay of immobilised antigen.

Sensitive assays for individual viral antibodies from cerebrospinal fluid have been achieved using techniques involving autoradiography. ${ }^{2}$ The lower limit of detection for such approaches has been of the order of $1 \mathrm{ng}$ per IgG band.' Depending on the specific activities of the radioisotope concerned-for example, Iodine 125-it may take several days to develop the final pattern. ${ }^{2}$ We have improved the sensitivity of the enzyme linked immunoassay system to a level comparable with the autoradiographic technique through the use of nitrocellulose blotting. ${ }^{34}$ The basic technique for quantification by planimetry has been described previously. ${ }^{5}$ We have extended this approach with the result that the enzyme linked technique is as sensitive, but more rapid than ${ }^{125} \mathrm{I}$ autoradiography and there is, of course, no need to handle radioactive materials with finite half life. In a separate paper, we have further extended this technique to quantify the immunoglobulin bound by measles antigen (see Discussion).

The quantification of paraproteins after electrophoretic separation (as opposed to immunochemical estimations) has been well documented and we have used an internal standard combined with the greater resolution of isoelectric focusing as contrasted with simple agarose electrophoresis. It is widely known that a single paraprotein band may give rise to multiple bands after focusing. This principle of obtaining a wider separation of individual clonal bands has allowed us to distinguish and then quantify by planimetry the individual bands of internal standard along with the native clones synthesised inside the central nervous system.

Accepted for publication 9 July 1984

\section{Material and methods}

AGAROSE GEL ELECTROPHORESIS

Agarose gel electrophoresis was carried out as described by Jeppson et al, ${ }^{6}$ using Litex Agarose type HSA (Miles Laboratories, Slough, UK). Samples consisted of undiluted serum, $1 \mu \mathrm{l}$ for $\operatorname{IgG}(\mathrm{Fc})$ studies, applied by means of a slotted mask (LKB, Bromma, Sweden). Gels were $100 \times 160 \times 0.8 \mathrm{~mm}$ Separation was effected at a constant $200 \mathrm{~V}$ with tap water cooling, until an albumin-bromophenol blue marker complex had migrated $4 \mathrm{~cm}$ from the origin? (about $1 \mathrm{~h}$ ). After electrophoresis dried gels were stained in Coomassie brilliant blue (Sigma).

\section{ISOELECTRIC FOCUSING}

Isoelectric focusing and immunoperoxidase staining after transfer of focused protein to cellulose nitrate was carried out as described by Walker et al. ${ }^{7}$ Diluted samples of IgG paraprotein serum were focused in agarose gels (materials from Pharmacia) with $20 \mathrm{~W} /$ gel, constant power, for $2000 \mathrm{~V} / \mathrm{h}$. Samples $(5-20 \mu \mathrm{l})$ of $\mathrm{IgG}$ paraprotein serum were applied. Dilutions ranged from $1 / 100$ to $1 / 10000$ in phosphate buffered saline (PBS). After the transfer stage, unoccupied binding sites on the nitrocellulose membrane were blocked by incubation in $0.5 \% \mathrm{wt} /$ vol bovine serum albumin (BSA) and $0.5 \% \mathrm{wt} / \mathrm{vol}$ gelatin in phosphate buffered saline, $\mathrm{pH} 7 \cdot 2$. Primary antisera were either sheep antihuman $\operatorname{IgG}(\mathrm{Fc})$ (Seward-Immunostics) or goat antihuman IgG (Fc) (Miles-Yeda) and were used at dilutions of $1 / 2000$ in PBS containing $0.5 \%$ BSA. Incubation was for $45 \mathrm{~min}$ at room temperature.

Nitrocellulose membranes were then washed five times, 2 min each in $100 \mathrm{ml}$ of PBS, and incubated either in horseradish peroxidase conjugated rabbit 
antisheep immunoglobulins (DAKO) diluted $1 / 2000$ in $0.5 \%$ BSA in PBS, or in horseradish peroxidase conjugated antigoat immunoglobulins (Miles-Yeda) diluted $1 / 2000$ in PBS, containing $0.5 \% \mathrm{BSA}$, for $45 \mathrm{~min}$ as appropriate. After washing, bands were visualised by the immunoperoxidase reaction as previously described. ${ }^{3}$

Cerebrospinal fluid total protein concentrations were measured by the nephelometric method of EJ Thompson outlined by Karlssohn and Alling. ${ }^{8}$ Serum total protein and albumin were measured by the biuret method and bromocresol green dye binding.

\section{SCANNING}

Reflective scanning of non-transparent nitrocellulose membranes and transmission scanning of agarose gels was performed in a Joyce Loebl Chromoscan 200 densitometric scanner. Membranes and gels were placed on a glass plate and covered by a second plate. Coomassie stained gels were scanned using light passed through a $589 \mathrm{~nm}$ filter. Nitrocellulose membranes were scanned using light passed through a $492 \mathrm{~nm}$ filter.

To assess the reproducibility of the method we measured areas of gamma globulin regions by planimetry using a computer aided bit pad (MOP$\mathrm{AMO}_{3}$, Kontron-Messgeräte $\mathrm{GmbH}$ ).

\section{STATISTICS}

Means and standard deviations were calculated from measurements of area; coefficients of variation were derived by dividing the standard deviation by the mean and multiplying by 100 .

\section{Results}

\section{DETERMINATION OF IgG PARAPROTEIN IN A}

\section{SERUM SAMPLE}

Agarose gel electrophoresis was carried out with $1 \mu \mathrm{l}$ of serum containing IgG paraprotein to determine the absolute amount of paraprotein in the serum. The total protein concentration of the serum sample was $69 \mathrm{~g} / \mathrm{l}$; albumin concentration was $39 \mathrm{~g} / \mathrm{l}$. From the densitometer scan of the agarose electrophoresis gel, integration of the globulin fractions were calculated: $\alpha_{1}=4.8 \% ; \alpha_{2}=25.5 \% ; \beta_{1}=$ $17.6 \% ; \beta_{2}=1.6 \% ; \gamma=50.8 \%$ which corresponds to $15 \cdot 23 \mathrm{~g} / \mathrm{l}$ as a subfraction of the $\gamma$ region.

\section{IgG PARAPROTEIN ON ISOELECTRIC}

\section{FOCUSING/IMMUNOBLOTTING}

The paraprotein containing serum was diluted $1 / 1000$ in PBS and a $5 \mu \mathrm{l}$ sample was applied to the gel. After isoelectric focusing, immunoblotting incubation with sheep antihuman IgG (Fc), incubation with rabbit antisheep immunoglobulin, and

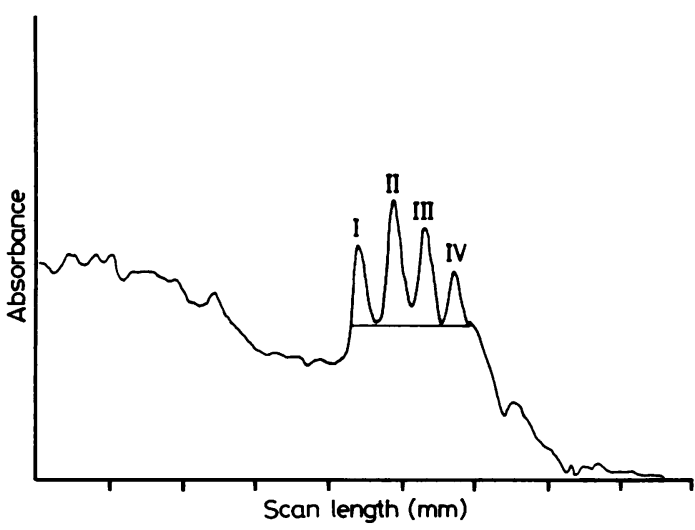

Fig. 1 Isoelectric focusing of IgG paraprotein containing human serum. Five microlitres of a 1/1000 dilution of paraprotein containing serum underwent isoelectric focusing/immunoblotting. After immunoperoxidase staining the nitrocellulose membrane was scanned with light passing through a $492 \mathrm{~nm}$ filter. Four sharp peaks are visible corresponding to four bands of IgG paraprotein. Peaks were integrated and relative amount of protein was calculated according to percentage of peak area.

staining, the nitrocellulose membrane was scanned and peaks were electronically integrated. Fig. 1 shows four sharp peaks corresponding to four sharp bands of IgG on the nitrocellulose membrane. According to relative percentages of the whole area covered by four peaks, the amount of protein corresponding to each band/peak was calculated as shown in Table 1.

\section{QUANTITATIVE EVALUATION OF ISOELECTRIC} FOCUSING WITH IgG PARAPROTEIN AS A STANDARD

Ten-microlitre samples of the paraprotein containing serum diluted $1 / 1000$ underwent isoelectric focusing/immunoblotting. Nitrocellulose membranes were incubated with sheep antihuman IgG (Fc), horseradish peroxidase labelled rabbit antisheep immunoglobulins, and stained. Gels were run on six different days and standard deviations and coefficients of variation were calculated for different

Table 1 Absolute amount of IgG paraprotein of four separate bands calculated from integrated peak areas after isoelectric focusing/immunoblotting of serum containing IgG paraprotein

\begin{tabular}{|c|c|c|c|c|c|}
\hline & \multicolumn{5}{|c|}{ Peak } \\
\hline & $I$ & $I I$ & III & $I V$ & Total \\
\hline $\begin{array}{l}\text { Area }\left(\mathrm{mm}^{2}\right) \\
\% \\
\operatorname{IgG}(\mathrm{ng})\end{array}$ & $\begin{array}{r}47 \\
19 \\
4\end{array}$ & $\begin{array}{r}84 \\
33 \\
8\end{array}$ & $\begin{array}{r}77 \\
30 \\
7\end{array}$ & $\begin{array}{r}45 \\
18 \\
4\end{array}$ & $\begin{array}{r}253 \\
100 \\
23\end{array}$ \\
\hline
\end{tabular}


days (between batch run) and on the same day (within batch run). Table 2 shows the coefficients of variation $(\mathrm{CV})$ of the peak areas for within batch and between batch runs. The variation on the same gel was in the range of $7 \%$. The variation from day to day was in the range of $20 \%$ (absolute-that is, not with standard).

\section{SENSITIVITY OF ISOELECTRIC FOCUSING OF IgG PARAPROTEIN}

A dilution series ranging from $1 / 100$ to $1 / 10000$ of paraprotein serum in PBS was prepared and isoelectric focusing with eight different dilutions was carried out. Fig. 2 shows the correlation between the amount of protein added to the gel and the size of the appropriate area on the densitometer scan after immunoblotting and staining of nitrocellulose membrane. As little as $5 \mathrm{ng}$ of paraprotein applied to the gel was still detectable, and one band corresponded to $1 \mathrm{ng}$ of $\mathrm{IgG}$, which is still visible by naked eye.

\section{USE OF IgG PARAPROTEIN ON THE SAME GEL AS AN INTERNAL STANDARD FOR OLIGOCLONAL SUBACUTE SCLEROSING PANENCEPHALITIS}

Ten microlitres of a suitable dilution of cerebrospinal fluid (containing $0.8 \mu l$ native cerebrospinal fluid) from a patient with subacute sclerosing panencephalitis was applied to an agarose gel. Total protein concentration was $0.42 \mathrm{~g} / \mathrm{l}$. Five microlitres of a 1/1000 dilution of IgG paraprotein (corresponding to $23 \mathrm{ng}$ ) containing serum was applied to the same track and isoelectric focusing was carried out three times as usual. Fig. 3 shows the nitrocellulose membrane after immunoblotting, incubation with first and second antibody, and staining. The nitrocellulose membrane was scanned and peak areas were integrated (Fig. 4). The last four peaks (5-8) correspond to serum paraprotein, while the first four peaks (1-4) correspond to oligoclonal subacute sclerosing panencephalitis bands. Table 3 shows the mean of areas and absolute amount of IgG bound to nitrocellulose as calculated from the relative percentage. The comparison of peak areas of paraprotein of known IgG content with peak areas of oligoclonal

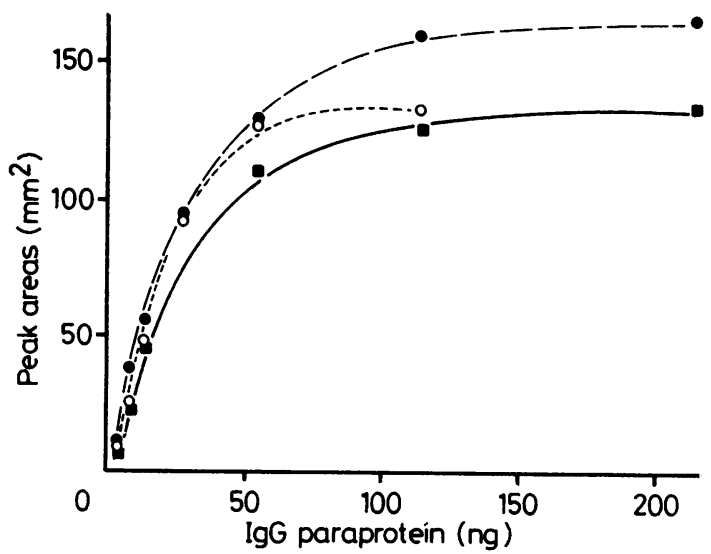

Fig. 2 Serial dilution of $\lg G$ paraprotein on isoelectric focusing/immunoblotting. One microlitre samples of IgG paraprotein containing human serum diluted $1 / 100$ to $1 / 10000$ underwent isoelectric focusing/immunoblotting on three separate days. After immunoperoxidase staining, nitrocellulose membranes were scanned and peaks were integrated. Peak areas $\left(\mathrm{mm}^{2}\right)$ were plotted against total amount of IgG paraprotein applied to the gel for one of four bands.

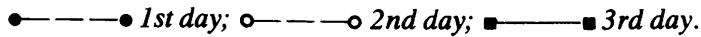

bands of subacute sclerosing panencephalitis cerebrospinal fluid allows an estimation of the $\mathrm{IgG}$ amount of different bands.

\section{Discussion}

The sensitivity of this assay is comparable to autoradiography in that $1 \mathrm{ng}$ of $\mathrm{IgG}$ banded protein is readily detected by unaided eye or by densitometry.' This lower limit can be further decreased by the use of a carrier protein such as albumin to block nonspecific electrostatic adsorption. Alternatively, the avadin-biotin system can also give further improvement in sensitivity. ${ }^{4}$ The results are also available within a few hours rather than days. ${ }^{3}$ The useful range is over the order of magnitude of $1-8 \mathrm{ng}$ per band. Greater levels of enzyme activity then begin to show saturation kinetics. The reproducibility of

Table 2 Variation of the integrated peak areas $\left(\mathrm{mm}^{2}\right)$ of human $\mathrm{IgG}$ paraproteins after isoelectric focusing/ immunoblotting of $(A)$ eight samples on the same gel and $(B)$ same sample over six days

\begin{tabular}{|c|c|c|c|c|c|c|c|c|}
\hline & \multicolumn{4}{|l|}{$A$} & \multicolumn{4}{|l|}{$B$} \\
\hline & \multicolumn{4}{|c|}{ Peak } & \multicolumn{4}{|c|}{ Peak } \\
\hline & $I$ & $I I$ & III & $I V$ & $I$ & $I I$ & III & IV \\
\hline $\begin{array}{l}\text { Mean } \\
\text { SD } \\
\text { CV (\%) }\end{array}$ & $\begin{array}{r}49 \\
5 \\
10\end{array}$ & $\begin{array}{r}77 \\
3 \\
4\end{array}$ & $\begin{array}{r}56 \\
3 \\
5\end{array}$ & $\begin{array}{r}35 \\
3 \\
9\end{array}$ & $\begin{array}{l}59 \\
11 \\
19\end{array}$ & $\begin{array}{r}81 \\
6 \\
7\end{array}$ & $\begin{array}{l}56 \\
10 \\
18\end{array}$ & $\begin{array}{r}27 \\
7 \\
32\end{array}$ \\
\hline
\end{tabular}

$\mathrm{SD}=$ standard deviation; $\mathrm{CV}=$ coefficient of variation. 


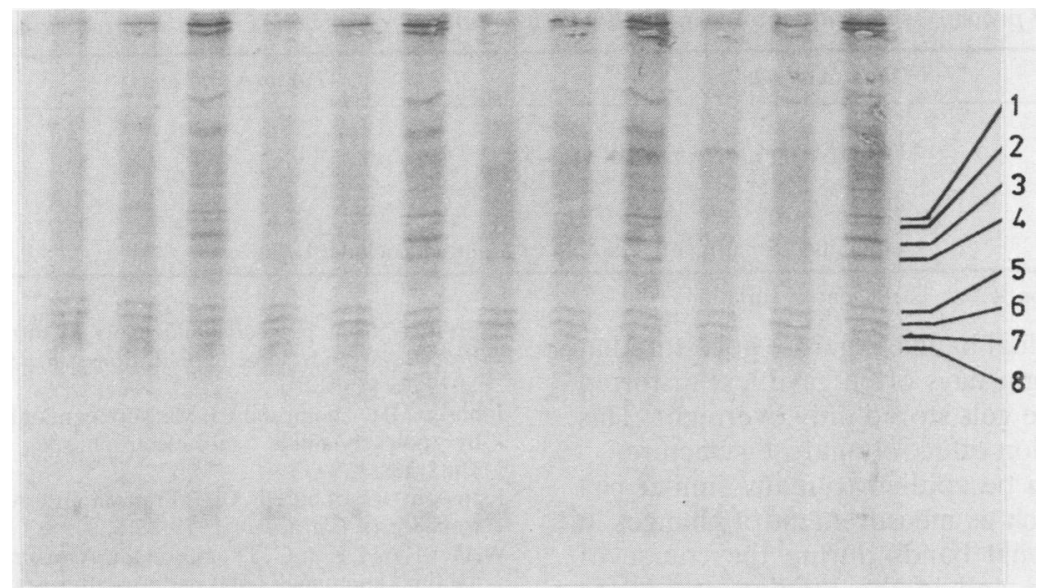

Fig. 3 Nitrocellulose membrane after isoelectric focusing/immunoblotting of subacute sclerosing panencephalitis cerebrospinal fuid (CSF) and IgG paraprotein as an internal standard. Ten microlitres of a suitable dilution of CSF (containing $0 \cdot 8 \mu l$ native CSF) from a patient with subacute sclerosing panencephalitis was applied to an agarose gel. In addition, $5 \mu l$ of a 1/1000 dilution of IgG paraprotein (corresponding to $23 \mathrm{ng}$ ) containing serum was applied to the same track and isoelectric focusing was carried out as usual. The nitrocellulose membrane was incubated with first and second antibody and stained. Eight sharp bands are visible. Bands 1, 2, 3, 4 correspond to oligoclonal IgG from CSF and bands 5, 6, 7, 8 correspond to $\mathrm{Ig} G$ paraprotein.

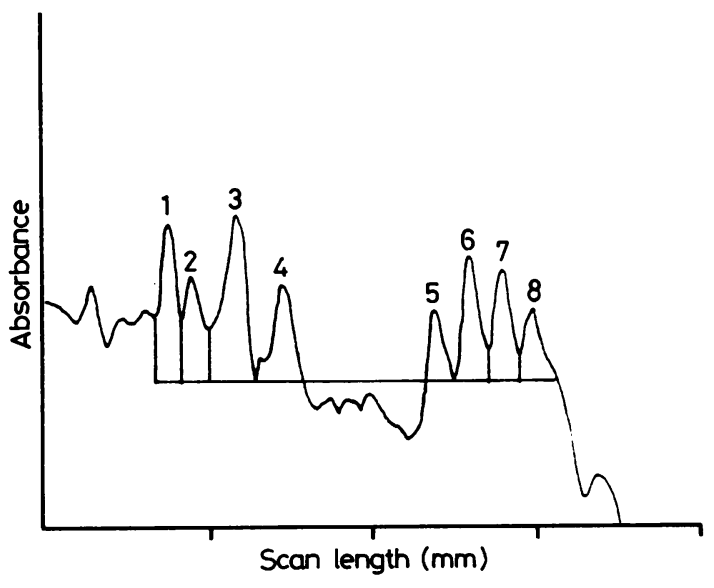

Fig. 4 Isoelectric focusing/immunoblotting of cerebrospinal fuid (CSF) from a patient with subacute sclerosing panencephalitis and the use of IgG paraprotein as an internal standard. Ten microlitres of a suitable dilution of CSF (containing $0.8 \mu l$ native CSF) from a patient with subacute sclerosing panencephalitis was applied to an agarose gel. In addition, $5 \mu$ lof a 1/1000 dilution of $\mathrm{IgG}$ paraprotein (corresponding to $23 \mathrm{ng}$ ) containing serum were applied to the same track and isoelectric focusing was carried out as usual. The nitrocellulose membrane was incubated with first and second antibody and stained. The densitometer scan shows eight individual peaks. Peaks 1, 2, 3,4 correspond to oligoclonal IgG from CSF and peaks 5, $6,7,8$ correspond to IgG paraprotein. the system using the internal standard is principally limited by the coefficient of variation of the planimeter-that is, about $5 \%$, which is similar to our previous experience with this principle using Coomassie stained proteins with the internal standard of transferrin. This coefficient of variation was also about $5 \%$ and was limited only by the planimetry. ${ }^{4}$ The day to day variability $(20 \%)$ has no practical consequence since each sample is referenced to the internal control. It merely illustrates the need for such a standard.

Certain factors influencing the reproducibility of quantification should be emphasised. Different immunoglobulin preparations change the intensity of IgG $(\mathrm{Fc})$ staining. Goat antihuman IgG $(\mathrm{Fc})$ and horseradish peroxidase labelled rabbit antigoat immunoglobulin (Miles-Yeda) were used on three different days on a 1/1000 dilution of IgG paraprotein containing serum. Immunoperoxidase staining of IgG bands was significantly weaker compared with experiments where sheep antihuman $\operatorname{IgG}(\mathrm{Fc})$ (Seward) and horseradish peroxidase labelled rabbit antisheep immunoglobulin (DAKO) were used. No qualitative change in the pattern was seen. In one series of IgG paraprotein the PBS used for dilution contained $0.5 \%$ BSA. This reduced non-specific binding to vials and pipettes and sensitivity was enhanced by a factor of two, especially at low concentrations of IgG (1/10 000). At higher concentrations the polyclonal background was enhanced and 
Table 3 Amount of protein of individual oligoclonal bands using paraprotein bands as an internal standard

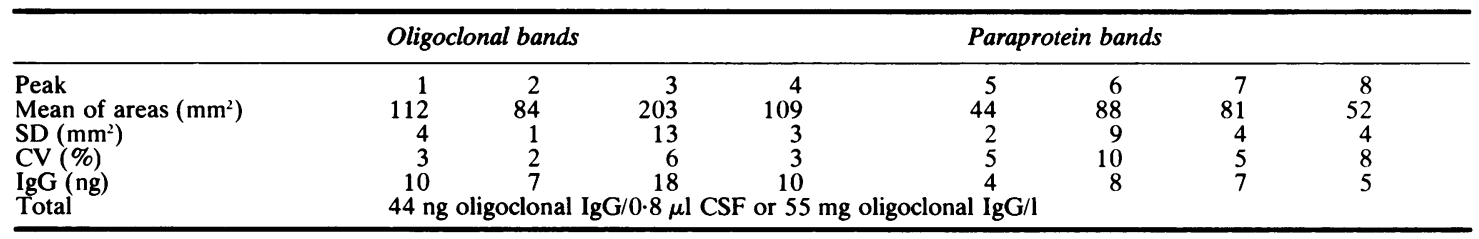

$\mathrm{SD}=$ standard deviation; $\mathrm{CV}=$ coefficient of variation.

masked the individual bands. Agarose gels stored at $4^{\circ} \mathrm{C}$ for at least eight days often gave less distorted bands than agarose gels stored only overnight. This implied a maturation effect of agarose structure.

The method can be applied to many similar circumstances, ${ }^{10} 11$ such as measurement of changes in individual oligoclonal bands during the course of multiple sclerosis ${ }^{12}$ and in the binding of IgG to measles or other viral antigens in encephalitis. ${ }^{13}$

This work was supported in part by a grant from the Medical Research Council. We gratefully acknowledge the skilful technical assistance of Miss Fay Storey.

\section{References}

' Kostulas VK, Link H. Agarose isoelectric focusing of unconcentrated CSF and radioimmunofixation for detection of oligoclonal bands in patients with multiple sclerosis and other neurological diseases. J Neurol Sci 1982;54:117-27.

${ }^{2}$ Nordal HJ, Vandvik B, Norrby E. Demonstration of electrophoretically restricted virus-specific antibodies in serum and cerebrospinal fluid by imprint electroimmunofixation. Scand J Immunol 1978; 7:381-8.

${ }^{3}$ Walker RWH, Keir G, Johnson MH, Thompson EJ. A rapid method for detecting oligoclonal IgG in unconcentrated CSF by agarose isoelectric focusing, transfer to cellulose nitrate and immunoperoxidase staining. J Neuroimmunol 1983;4:141-8.

${ }^{4}$ Towbin H, Staehelin T, Gordon J. Electrophoretic transfer of proteins from polyacrylamide gels to nitrocellulose sheets: Procedure and some applications. Proc Natl Acad Sci 1979; 76:4350-4.

${ }^{5}$ Johnson MH, Thompson EJ. Measurement of body fluid proteins by polyacrylamide gel electrophoresis. J Clin Pathol 1982;35: 1328-33.

- Jeppsson JO, Laurell CB, Franzen B. Agarose gel electrophoresis. Clin Chem 1979;25:629-38.

${ }^{7}$ Walker RWH, Keir G, Thompson EJ. Assessment of cerebrospinal fluid immunoglobulin patterns after isoelectric focusing. $J$ Neurol Sci 1983;58:123-34.

${ }^{*}$ Karlsson B, Alling C. A comparative study of three approaches to the routine quantitative determination of spinal fluid total proteins. Clin Chim Acta 1980;105:65-73.

"Yolken RH, Leister FJ, Whitcomb LS, Santosham M. Enzyme immunoassays for the detection of bacterial antigens utilising biotin-labelled antibody and peroxidase biotin-avidin complex. J Immunol Meth 1983;56:319-27.

${ }^{10}$ Sutton R, Wrigley CW, Baldo BA. Detection of IgE- and IgGbinding proteins after electrophoretic transfer from polyacrylamide gels. J Immunol Meth 1982;52:183-94.

" Karcher D, Lowenthal A, Thormar H, Noppe M. Serological identification of viral antigens after electrophoretic transfer. $J$ Immunol Meth 1981;43:175-9.

${ }_{12}$ Thompson EJ, Kaufmann P, Rudge P. Sequential changes in oligoclonal patterns during the course of multiple sclerosis. Neurol Neurosurg Psychiat 1983;46:547-50.

${ }^{13}$ Mayle S, Keir G, Thompson EJ. Viral immunoblotting-a sensitive method for detecting viral specific oligoclonal bands in unconcentrated cerebrospinal fluid. Bioscience Reports 1984; 4:505-10.

Requests for reprints to: Dr E J Thompson, Department of Neurochemistry, Institute of Neurology, Queen Sqaure, London WC1N 3BG, England. 